\title{
COMPARATIVE STUDY OF LICHTENSTEIN VERSUS DESARDA REPAIR FOR INGUINAL HERNIA
}

\author{
Sowmya G. $R^{1}$, Deepak G. Udapudi ${ }^{2}$ \\ ${ }^{1}$ Assistant Professor, Department of Surgical Gastroenterology, Kempegowda Institute of Medical Sciences, Bangalore. \\ 2 Professor, Department of General Surgery, JJMMC, Davangere.
}

\section{ABSTRACT}

\section{BACKGROUND}

Inguinal hernia repair is the most frequently performed operation in any general surgical unit. The Bassini's, Shouldice and other tissue-based techniques are still being acceptable for primary inguinal hernia repair. Desarda's technique is originally a tissue based hernia repair using an undetached strip of external oblique aponeurosis to strengthen the posterior wall of the inguinal canal. The aim of the present study was to compare Lichtenstein hernia repair and Desarda herniorrhaphy.

\section{METHODS}

A total of 40 patients with primary unilateral inguinal hernia were subjected either to Desarda herniorrhaphy or Lichtenstein hernioplasty. The patients were followed in terms of recurrence rate, post-operative complications, convalescence, chronic pain and cost effectiveness.

\section{RESULTS}

During the followup all patients had either mild or moderate pain, but the pain intensity was more in Lichtenstein repair compared to Desarda repair in the immediate postoperative period. In Lichenstein repair patients had chronic groin pain even at the end of one year, but none of the patients in Desarda repair had chronic groin pain. Complications such as seroma and wound infection were less in Desarda repair. Time taken to resume normal activities was significantly less in case of Desarda herniorrhaphy; however, there was no recurrence observed in both the groups during the followup period. Average cost incurred for Desarda repair was significantly less than Lichtenstein repair.

\section{CONCLUSION}

Lichtenstein method of hernia repair is simple and safe. But the mesh prosthesis has its drawbacks. Desarda hernia repair is based on physiological principles and the results are good with less convalescence period and fewer recurrences and no chronic groin pain. It is more cost effective.

\section{KEYWORDS}

Inguinal Hernia, Prolene Mesh, Mesh versus Non-Mesh, Tension Free Repair, External Oblique Aponeurosis, Desarda versus Lichtenstein.

HOW TO CITE THIS ARTICLE: Sowmya G. R, Deepak G. Udapudi. "Comparative Study of Lichtenstein versus Desarda Repair for Inguinal Hernia.” Journal of Evolution of Medical and Dental Sciences 2015; Vol. 4, Issue 97, December 03; Page: 16261-16265, DOI: $10.14260 /$ jemds/2015/2397

\section{INTRODUCTION}

The estimated lifetime risk for inguinal hernia is $27 \%$ for men and 3\% for women. ${ }^{1}$ Reports on the outcome of inguinal hernia surgery show that recurrence rate 5 years after operation can vary from 0.1 to over $20 \%$. Classically done operations today are tension repairs like Bassini, Shouldice or MacVay's repairs and tension free repairs like repairs done with mesh, plug and mesh or PHS (Prolene Hernia System). All tension repairs have high rate of recurrences and postoperative pain. Sutures are under tension even at rest and gets aggravated during contractions and scar shrinkage in healing process. Therefore, tension free repairs using mesh prosthesis are being preferred. But then there are many associated complications of a foreign body. Laparoscopic hernia surgery reduces pain and duration of stay, but associated with its own complications associated with general anaesthesia and instrumentations in addition to the mesh placed inside the abdomen.

Financial or Other, Competing Interest: None.

Submission 06-11-2015, Peer Review 07-11-2015,

Acceptance 24-11-2015, Published 03-12-2015.

Corresponding Author:

Sowmya G. $R$,

No. 38, D Main Road, $9^{\text {th }}$ East,

Jayanagar-560069,

Bangalore.

E-mail: sowmyagraj6@gmail.com

DOI:10.14260/jemds/2015/2397
According to EHS guidelines, mesh-based techniques the Lichtenstein technique in particular and endoscopic methods are recommended for treatment of symptomatic primary inguinal hernia in adult men and Shouldice method has been acknowledged to be acceptable as well. ${ }^{2}$ Lichtenstein method of hernia repair is simple and safe. But the mesh prosthesis has its drawbacks. Mesh works as a mechanical barrier. It does not give mobile and physiologically dynamic posterior wall. ${ }^{3}$ The synthetic prostheses can create new clinical problems, such as foreign body sensation in the groin, discomfort and abdominal wall stiffness, which may affect the everyday functioning of the patient. ${ }^{4}$

Migration of the mesh from the primary site of implantation in the abdominal cavity is one of the most dangerous complications. ${ }^{5-7}$ Surgical site infections are more frequent after hernia treatment using mesh.8,9 Intense chronic inflammatory process typically associated with foreign body reactions around the mesh prosthesis may produce meshoma or plugoma tumors, the treatment of which becomes a new surgical challenge.10-12 Additionally, procreation and sexual function are partly seriously affected after surgical hernia treatment with mesh.6,13 Desarda repair has removed all drawbacks of both types of repairs. There is no tension on suture lines as seen in tension repairs and there is no foreign body used like mesh repairs. 
Desarda repair for inguinal hernia is based on the concept of providing a strong, mobile and physiologically active posterior wall. An undetached strip of the external oblique aponeurosis gives replacement to the absent aponeurotic element in the posterior wall and the additional muscle strength is given by the external oblique muscle to keep it physiologically active. Mobility is not affected because there is minimal or no fibrosis and posterior wall remains mobile. ${ }^{14-17}$

\section{METHODOLOGY}

This comparative study of Lichtenstein versus Desarda repair for inguinal hernia was conducted from the patients admitted with the diagnosis of unilateral primary inguinal hernia in a Medical College Hospital from June 2006 to May 2008. The patients were subjected to either Lichtenstein or Desarda method of hernia repair. Patients were included in the study based on the inclusion and the exclusion criteria as mentioned below.

\section{Inclusion Criteria}

1. Men 25 years of age or older with primary unilateral inguinal hernia.

\section{Exclusion Criteria}

1. Women.

2. Bilateral inguinal hernia.

3. Recurrent inguinal hernia.

4. Complicated inguinal hernia.

All procedures were done under Spinal anesthesia. For Lichtenstein hernioplasty, a 3-inch x 6-inch polypropylene mesh made by Ethicon Company was used. The mesh is -0.5 $\mathrm{mm}$ thick and has burst strength of approximately $14 \mathrm{~kg} / \mathrm{cm}^{2}$. It is sterilized by Ethylene oxide gas by the manufacturer. Polypropylene 2-0 was used to suture the mesh in place. Similarly for Desarda repair, an un-detached strip of the External Oblique Aponeurosis (EOA) is sutured to the inguinal ligament below and the muscle arch above, behind the cord to form a new posterior wall using $1 / 0$ polypropylene interrupted sutures (Fig 1, Fig 2, Fig 3).

The patients were followed up for postoperative pain, which was evaluated using Visual Analogue Scale, wound hematoma, wound seroma, wound infection. Patients were assessed for postoperative pain using Visual Analogue Scale on day 1, day 3 and on day 7. Visual Analogue Scale consists of a $10 \mathrm{~cm}$ line anchored at one end by a label as no pain and at the other end by a label as severe pain. We translated this for documentation as 1-3 mild pain, 3-7 moderate pain, and 7-10 severe pain. Sutures were removed on the $7^{\text {th }}$ postoperative day and the patients discharged if there was no wound infection, were ambulatory, were taking orally and felt comfortable.

Patients were called to the Outpatient Department and followup was done after 1 month, 6 months and 1 year for complications like chronic groin pain (Inguinodynia), time taken to resume normal activity and recurrence. Cost effectiveness of the two procedures was compared.

\section{RESULTS}

Forty cases of unilateral primary inguinal hernia were included in the study after taking their consent. They were subjected to either Lichtenstein or Desarda method of hernia repair. Evaluation of all the patients included in the study was done regarding the history, physical findings, operative findings and postoperative complications. Twenty patients underwent repair with prolene mesh and twenty patients underwent Desarda herniorrhaphy.
The patients were followed up at one month, six months and at one year interval for any complication or recurrence.

Any recurrence of hernia or death of patient was considered an end point.

The mean age of presentation in Lichtenstein group was $44.1 \pm 12.9$ and in Desarda $46.6 \pm 16.2$. There was no significant difference in the age in both the groups. In both of the groups, all patients presented with swelling in the groin $(100 \%)$ and pain was present in 11 cases (55\%) of patients in Lichtenstein and 12 cases $(60 \%)$ of patients in Desarda group. Both the groups presented more commonly with right than left sided inguinal hernias. In the study $12(60 \%)$ cases had indirect and $8(40 \%)$ cases had direct type of hernia in Lichtenstein group and 15(75\%) had indirect and 5(25\%) cases had direct type of hernia in Desarda group. Associated comorbidities are shown in the Table 1.

On day 1 all patients (100\%) had either mild or moderate pain, but the pain intensity was more in Lichtenstein repair compared to Desarda repair. On day 3 $65 \%$ of patients had mild pain and $20 \%$ of patients had moderate pain in Lichtenstein group, whereas $55 \%$ of patients had mild pain and $10 \%$ of patients had moderate pain; and on day $710(50 \%)$ cases had mild pain in Lichtenstein and 5(25\%) cases had mild pain in Desarda; however, the difference was not statistically significant. More number of complications was observed in Lichtenstein repair $(20 \%)$ with $2(10 \%)$ cases having seroma and $2(10 \%)$ cases having infection of the wound. In Desarda repair 2(10\%) patients had complications, one each having seroma and infection of the wound. However, it was not statistically significant [Table2].

During followup period at one month and six months, $7(35 \%)$ cases and $4(20 \%)$ cases persisted to have mild pain respectively in Lichtenstein repair, whereas none of the patients in Desarda repair had any kind of pain which is statistically significant. Two $(10 \%)$ patients continued to have chronic pain at the end of 1 year in Lichtenstein group [Table 3]. Time taken to resume normal activities was significantly less in case of Desarda herniorrhaphy as compared to Lichtenstein hernioplasty (Table 5). There was no recurrence observed in both the groups during the followup period.

Average cost incurred for Lichtenstein repair was Rs.2440/-, whereas for Desarda repair the cost incurred was significantly less with average cost of Rs.1200/- per patient [Table 6].

\begin{tabular}{|c|c|c|}
\hline Symptoms & $\begin{array}{c}\text { Lichtenstein } \\
\text { n (\%) }\end{array}$ & $\begin{array}{c}\text { Desarda } \\
\text { n (\%) }\end{array}$ \\
\hline Swelling & $20(100)$ & $20(100)$ \\
\hline Pain & $11(55)$ & $12(60)$ \\
\hline \multicolumn{3}{|c|}{ Side Affected } \\
\hline Right & $14(70)$ & $15(75)$ \\
\hline Left & $6(30)$ & $5(25)$ \\
\hline \multicolumn{3}{|c|}{ Type } \\
\hline Direct & $8(40)$ & $5(25)$ \\
\hline Indirect & $12(60)$ & $15(75)$ \\
\hline \multicolumn{3}{|c|}{ Associated Factors } \\
\hline Sm & $5(25)$ & $3(15)$ \\
\hline BEP & $1(5)$ & $2(10)$ \\
\hline DM & $1(5)$ & $2(10)$ \\
\hline HTN & $2(10)$ & $1(5)$ \\
\hline BA & $1(5)$ & $1(5)$ \\
\hline DM+HTN & $1(5)$ & $1(5)$ \\
\hline DM+BEP & $1(5)$ & - \\
\hline NIL & $8(40)$ & $10(50)$ \\
\hline Table 1: Presentation, Side Affected \\
\hline \multicolumn{2}{|c|}{ and Comorbidities } \\
\hline
\end{tabular}




\begin{tabular}{|c|c|c|}
\hline Complications & $\begin{array}{c}\text { Lichtenstein } \\
\mathbf{n}(\%)\end{array}$ & $\begin{array}{c}\text { Desarda } \\
\mathbf{n}(\%)\end{array}$ \\
\hline Hematoma & - & - \\
\hline Seroma & $2(10)$ & $1(5)$ \\
\hline Infection & $2(10)$ & $1(5)$ \\
\hline Normal & $16(80)$ & $18(90)$ \\
\hline Total & $20(100)$ & $20(100)$ \\
\hline \multicolumn{2}{|c|}{ Table 2: Comparison of Immediate } \\
Postoperative Complications \\
\hline
\end{tabular}

\begin{tabular}{|c|c|c|c|c|c|c|c|c|c|}
\hline & \multicolumn{4}{|c|}{ Lichtenstein } & \multicolumn{3}{c|}{ Desarda } & $\begin{array}{c}\text { Fisher's } \\
\text { Test } \\
\text { P value }\end{array}$ \\
\cline { 2 - 9 } & $\mathbf{N}$ & $\mathbf{m}$ & $\mathbf{M}$ & $\mathbf{S}$ & $\mathbf{N}$ & $\mathbf{m}$ & $\mathbf{M}$ & $\mathbf{S}$ & \\
\hline $\begin{array}{c}1 \\
\text { month }\end{array}$ & $\begin{array}{c}13 \\
(65)\end{array}$ & $\begin{array}{c}7 \\
(35)\end{array}$ & - & - & $\begin{array}{c}20 \\
(100)\end{array}$ & - & - & - & $<0.05 \mathrm{~S}$ \\
\hline $\begin{array}{c}6 \\
\text { months }\end{array}$ & $16(80)$ & $4(20)$ & - & - & $\begin{array}{c}20 \\
(100)\end{array}$ & - & - & - & $<0.05 \mathrm{~S}$ \\
\hline I year & $18(90)$ & $2(10)$ & - & - & $\begin{array}{c}20 \\
(100)\end{array}$ & - & - & - & $\begin{array}{c}>0.05 \\
\text { NS }\end{array}$ \\
\hline \multicolumn{6}{|c|}{ Table 3: Comparison of Chronic Pain } \\
(Numbers in parenthesis indicate percentages)
\end{tabular}

\begin{tabular}{|c|c|c|c|c|}
\hline Groups & Range (days) & Mean \pm SD & $\mathrm{t}^{*}$ & $\mathbf{P}$ \\
\hline Lichtenstein & $7-15$ & $10.7 \pm 2.7$ & \multirow{2}{*}{2.18} & \multirow{2}{*}{$<0.05 \mathrm{~S}$} \\
\hline Desarda & $5-15$ & $8.7 \pm 3.1$ & & \\
\hline \multicolumn{5}{|c|}{$\begin{array}{c}\text { Table 4: Comparison of Time Taken to Resume } \\
\text { Normal Activities or Convalescence Period }\end{array}$} \\
\hline Groups & Range (Rs) & Mean \pm SD & $\mathbf{t}^{*}$ & $\mathbf{P}$ \\
\hline Lichtenstein & $1750-3250$ & $2440 \pm 394$ & \multirow{2}{*}{10.8} & \multirow{2}{*}{$<0.05 \mathrm{~S}$} \\
\hline Desarda & \begin{tabular}{l|l}
$800-1800$ & \\
\end{tabular} & $1208 \pm 320$ & & \\
\hline \multicolumn{5}{|c|}{ Table 5: Cost Analysis } \\
\hline
\end{tabular}

DISCUSSION: Inguinal hernia is a very common condition afflicting mankind. All inguinal hernias share the common feature of emerging through the myopectineal orifice of Fruchaud. The weak and physiologically inactive posterior wall of inguinal canal leads to hernia formation. Therefore, the aim of hernia repair should be to provide a strong, mobile and physiologically dynamic posterior wall. The mean recurrence rate for the standard Lichtenstein procedure is about $1 \%$ in hernia specialized centers, but can be much higher in other hospitals (About 4\%), and the reported rate even reaches $18 \%$ in some articles. ${ }^{18}$

The data published so far for other mesh techniques vary - 0 to $4.2 \%$ recurrences for Prolene Hernia System (PHS), 0 to $4 \%$ for Rutkow, 1.6 to $19.0 \%$ for the Transabdominal Pre-Peritoneal inguinal hernia repair (TAPP).18-20 Postoperative complications reported in the available literature are between $15 \%$ and $28 \% .{ }^{21,22}$ The most frequently reported complications were hematoma, seroma, surgical-site infection, chronic pain, and recurrence. ${ }^{23}$ Death and other complications were rare, but were also reported. ${ }^{23,24}$

In our study, there were no statistically significant differences between the patients demographics in both groups and also there was no recurrence observed in both the groups during the followup period. Although, there was no statistically significant difference observed in the immediate post-operative pain, $20 \%$ of cases had chronic groin pain at the end of one year in Lichenstein group, which was statistically significant.

The post-operative complications between the two groups were comparable. Increased rate of seromas were noted in Lichtenstein method may be the effect of synthetic mesh on surrounding tissues. This is consistent with other studies. 25,26
The operation described by Lichtenstein is simple and safe and achieves all the goals of modern hernia surgery.

But the mesh prosthesis has its own drawbacks. First, it is not available in every part of the world. Second, it increases the cost of the operation. Third, because the groin is a mobile area there is a tendency for the mesh to fold, wrinkle or curl. Mesh prostheses lose approximately $20 \%$ of their size, in vivo, through shrinkage. The slightest movement of the mesh from the sutured area, due to the aforementioned factors is a leading cause of failure of mesh repair of inguinal hernias. Further, chronic groin sepsis following mesh repair is more frequent than reported previously and complete removal of mesh is required to treat this condition. Mesh works as a mechanical barrier.

It does not give mobile and physiologically dynamic posterior wall. The theory of mesh repair is also based on fibroblasts proliferation in the mesh and the degree and magnitude of fibroblast proliferation is also affected by the aging process.

Alterations in collagen synthesis may be responsible for the development of inguinal herniation. Read published a review of the role of protease-antiprotease imbalance in the pathogenesis of herniation along with aging process of the tissues. This is true in the hernia repairs such as the Bassini, McVay, and Shouldice that use weakened internal oblique and transversus abdominis muscles for repair. The aging process is minimum in the tendons and aponeurosis, so a strip of the external oblique which is tendo-aponeurotic is the best alternative to the mesh.

The Desarda technique for inguinal hernia repair is a tissue-based method where an undetached, movable aponeurotic strip that "Physiologically" enforces the posterior wall of the inguinal canal. The technique is original, new and different from the historical methods using the external oblique aponeurosis, proposed initially by McArthur and Andrews or Zimmermann.27,28 Moreover, the Desarda technique of hernia repair does not need any costly mesh or laparoscopic instruments. This makes this repair highly cost effective. A cost effective repair that gives excellent results will go a long way in reducing health care cost in those days of cost ergonomics.

Economic issues are not the only considerations. The use of synthetic material is still controversial in young patients. The effect of polypropylene placement or other synthetic mesh inside human organism for a lifetime is still unknown. Also, data are appearing about sexual impairment after mesh implantation and as a result many surgeons try to avoid mesh prostheses for hernia treatment in young patients. Also the Desarda method, a tissue-based technique, can be used in a contaminated surgical field, usually seen during operations for strangulated hernias.

\section{CONCLUSION}

The study was designed to compare Lichtenstein and Desarda type of inguinal hernia repair. Though it requires studying large number of patients and a longer followup period, based on the results of our study following conclusions can be drawn.

1. The Desarda and Lichtenstein methods of primary inguinal hernia repair do not differ in the means of procedure, complexity and surgery time.

2. The number of local complications and pain intensity were however more in Lichtenstein group compared to Desarda.

3. Time taken to resume normal activities was significantly more in Lichtenstein group. The patients after Desarda and Lichtenstein hernia repair were satisfied with the surgery results. 
4. No recurrence was seen during the followup period in both the groups. Desarda technique is based on the physiological principles. This operation is simple to perform, does not require foreign body like mesh or complicated dissection of the inguinal floor as in Bassini/Shouldice and is cost effective.

\section{BIBLIOGRAPHY}

1. Primatesta $P$, Goldacre MJ (1996) Inguinal hernia repair: incidence of elective and emergency surgery, readmission and mortality. Int J Epidemiol 25:835-839.

2. Simons MP, Aufenacker T, Bay-Nielsen M, et al. (2009) European Hernia Society guidelines on the treatment of inguinal hernia in adult patients. Hernia 13:343-403.

3. Vrijland WW, Van Den Tol MP, Luijendijk RW, et al. Randomized clinical trial of non-mesh versus mesh repair of primary inguinal hernia. Br J Surg 2002;89:293-297.

4. D'Amore L, Gossetti F, Vermeil V, et al. (2008) Long-term discomfort after plug and patch hernioplasty. Hernia 12:445-446.

5. Jeans S, Williams GL, Stephenson BM (2007) Migration after open mesh plug inguinal hernioplasty: a review of the literature. Am Surg 73:207-209.

6. Ott V, Groebli Y, Schneider R (2005) late intestinal fistula formation after incisional hernia using intraperitoneal mesh. Hernia 9:103-104.

7. Benedetti M, Albertario S, Niebel T, et al. (2005) Intestinal perforation as a long-term complication of plug and mesh inguinal hernioplasty: case report. Hernia 9:93-95.

8. Genc V, Ensari C, Ergul Z, et al. (2010) A very late-onset deep infection after prosthetic inguinal hernia repair. Chirurgia (Bucur) 105:555-557.

9. Scott NW, McCormack K, Graham P, et al. (2002) Open mesh versus non-mesh for repair of femoral and inguinal hernia. Cochrane Database Syst Rev CD002197.

10. McRoy LL (2010) Plugoma and the prolene hernia system. J Am Coll Surg 212:424 author reply 424-425.

11. Miller JP, Acar F, Kaimaktchiev VB, et al. (2008) Pathology of ilioinguinal neuropathy produced by mesh entrapment: case report and literature review. Hernia 12:213-216.

12. Fawole AS, Chaparala RPC, Ambrose NS (2006) Fate of the inguinal hernia following removal of infected prosthetic mesh. Hernia 10:58-61.

13. Uzzo RG, Lemack GE, Morrissey KP, et al. (1999) the effects of mesh bioprosthesis on the spermatic cord structures: a preliminary report in a canine model. J Urol 161:1344-1349.

14. Desarda MP, Ghosh A. Comparative study of open mesh repair and Desarda's no mesh repair in a setup of a district hospital in India. The East \& Central African Journal of Surgery. 2006;11:2.

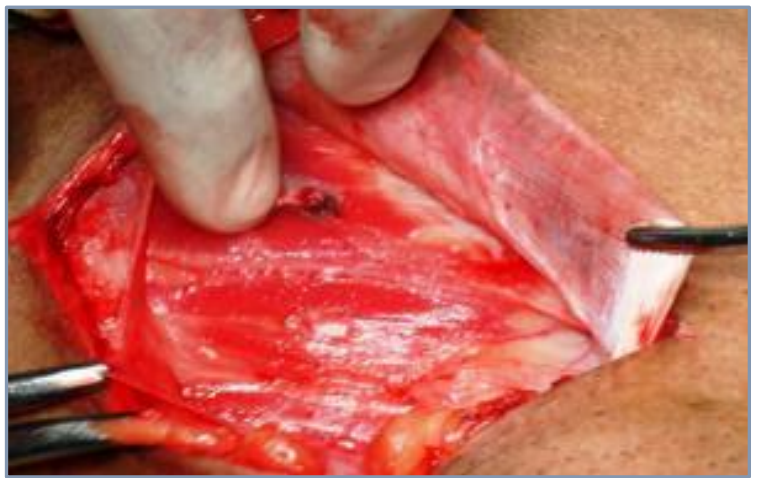

Fig. 1: Dissection of Upper and Lower Flaps of External Oblique Aponeurosis
15. Desarda MP. New method of inguinal hernia repair-A new solution. ANZ J Surg 2001;71:241-44.

16. Desarda MP. Physiological repair of inguinal hernia-A new technique (study of 860 patients). Hernia. 2006;10:143146.

17. Desarda MP. Inguinal herniorraphy with an undetached strip of external oblique aponeurosis: A new approach used in 400 patients. Eur J Surg 2001 Jun;167(6):443-8.

18. Eklund A, Rudberg C, Smedberg S, et al. (2006) Shortterm results of a randomized clinical trial comparing Lichtenstein open repair with totally extraperitoneal laparoscopic inguinal hernia repair. Br J Surg 93:10601068.

19. Hasegawa S, Yoshikawa T, Yamamoto Y, et al. (2006) Long-term outcome after hernia repair with the prolene hernia system. Surg Today 36:1058-1062.

20. Adamonis W, Witkowski P, Smietanski M, et al. (2006) is there a need for a mesh plug in inguinal hernia repair? Randomized, prospective study of the use of Hertra 1 mesh compared to PerFix Plug. Hernia 10:223-228.

21. Bittner R, Sauerland S, Schmedt CG (2005) Comparison of endoscopic techniques vs Shouldice and other open nonmesh techniques for inguinal hernia repair: a metaanalysis of randomized controlled trials. Surg Endosc 19:605-615.

22. Schmedt CG, Sauerland S, Bittner R (2005) Comparison of endoscopic procedures vs. Lichtenstein and other open mesh techniques for inguinal hernia repair: a metaanalysis of randomized controlled trials. Surg Endosc 19:188-199.

23. Robinson TN, Clarke JH, Schoen J, et al. (2005) Major mesh related complications following hernia repair: events reported to the Food and Drug Administration. Surg Endosc 19:1556-1560.

24. Bay-Nielsen M, Kehlet H (2008) Anaesthesia and postoperative morbidity after elective groin hernia repair: a nation-wide study. Acta Anaesthesiol Scand 52:169-174.

25. Lichtenstein IL. Herniorraphy. A personal experience with 6321 cases. Am J Surg 1987;153:553-559.

26. Nordin P, Bartelmess P, Jansson C, Svensson C and Edlund G. Randomized Trial of Lichtenstein Versus Shouldice Hernia Repair in General Surgical Practice. Br J Surg 2002;89:45-49.

27. Stephensen BM. Complications of Open Groin Hernia Repairs. Surg Clin N Am 2003;83:1255-1278.

28. Alfieri S, Rotondi F, Giorgio AD, Fumagalli U. Salzano A, Micelli DD, et al. Influence of Preservation Versus Division of Ilioinguinal Iliohypogastric and Genital Nerves during Open Mesh Herniorraphy -Prospective Multicentric Study of chronic pain. Ann Surg 2006;243(4):553-558.

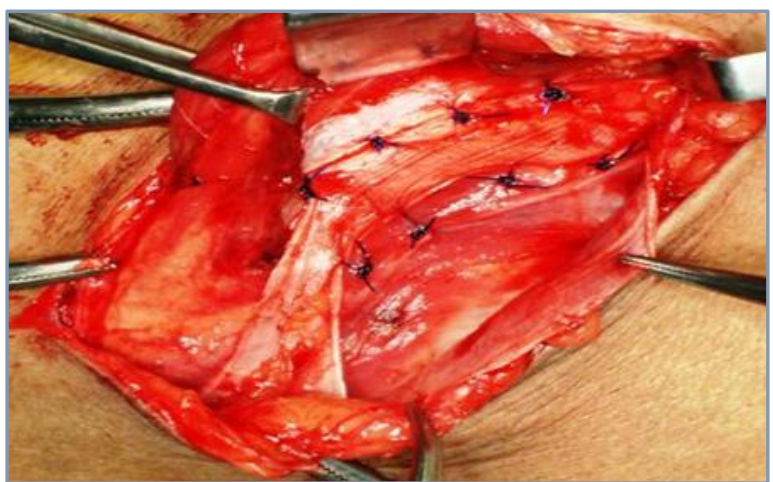

Fig. 2: External Oblique Sutured to Inguinal Ligament Below and to the Conjoint Tendon Above 


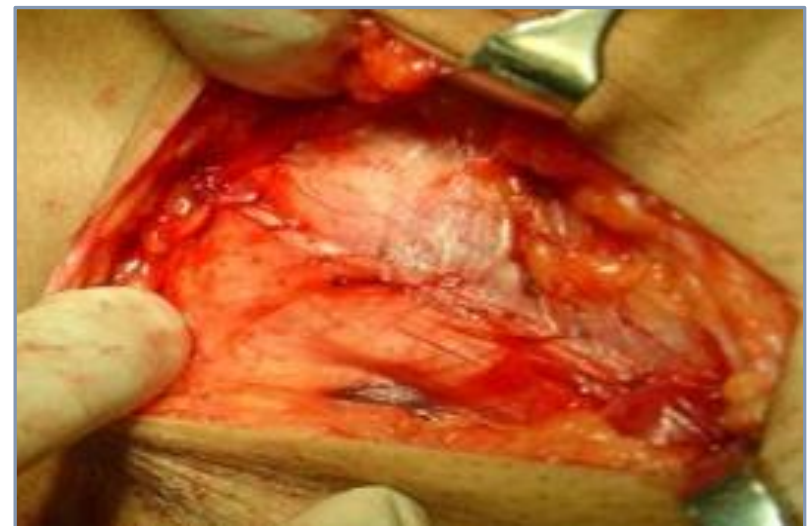

Fig. 3: Closure of External Oblique Aponeurosis

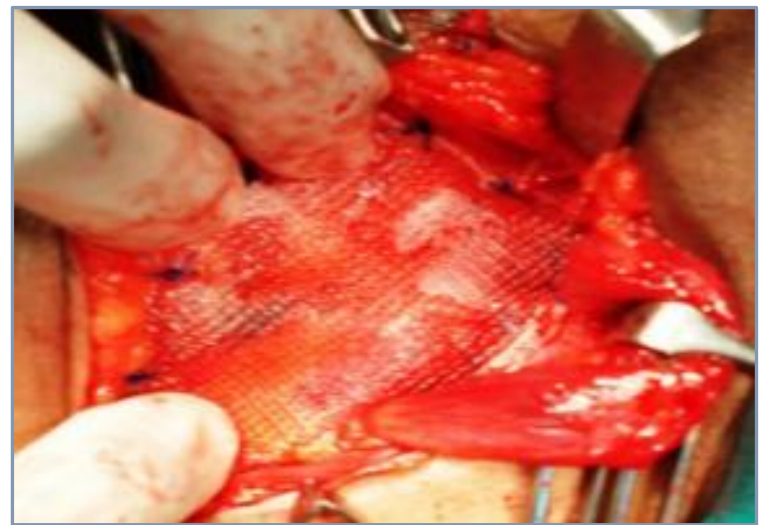

Fig. 4: Lichtenstein's Mesh Repair 